\title{
Recommender Systems for Software Requirements Negotiation and Prioritization
}

\author{
Shahnawaz Ahmad \\ M. Tech. Scholar, Department of Computer \\ Science and Engineering, Al-Falah School of \\ Engineering and Technology Dhauj, Faridabad, \\ Haryana, India.
}

\author{
Mohd. Sadiq \\ Computer Engineering Section, UPFET, Jamia \\ Millia Islamia (A Central University) \\ New Delhi-110025, India.
}

\begin{abstract}
Recommender systems recommend products to customers based on ratings or past customer activities. It has the effect of guiding users in a personalized way to achieve remarkable objects in a large space of achievable options. In this paper, we proposed a method which is based on recommender systems for software requirements negotiation and prioritization. Finally, the utilization recommender system is demonstrated with the help of an example.
\end{abstract}

\section{Keywords}

Requirements Engineering, Goal Oriented Requirements Engineering, Recommender Systems, and Fuzzy Logic.

\section{INTRODUCTION}

Recommender Systems (RSs) gather information on the preferences of its stakeholders for a set of items (e.g., movies, songs, jokes, gadgets, application, websites, travel destinations, e-learning material etc.). RS may use demographic features of stakeholders like age, nationality, gender etc. The information can be obtained explicitly (typically by collecting stakeholders ratings) or implicitly [12, 13, 14] (typically by monitoring stakeholders behavior, like songs heard, applications downloaded, web sites visited, and books read). RS make use of dissimilar sources of information for providing stakeholders with calculations and recommendations of items [15].

Software requirements can be broadly classified into two parts, i.e. functional requirements and non functional requirements. In literature, we have identified that lack of requirements understanding and also lack of stakeholders participations are the main reasons for software failures [3]. Stakeholder identification is an important activity of requirements elicitation [3]. In requirements elicitation process, requirements are identified from the stakeholders as the primary resources, and also on the basis of the careful analysis of the organization, the application domain and business, where the system will be deployed [4]. Requirements elicitation process includes interviews, questionnaires, user observation, workshops, brainstorming, use_cases, goal concepts, etc. [5].

In literature, several methods have been proposed to elicit the requirements like use case diagram, system modeling language (SysML), and goal oriented methods like Knowledge Acquisition for Automated Specification (KAOS), $i^{*}$, Goal Oriented Idea Generation (GOIG), and Attributed Goal Oriented Requirements Analysis (AGORA) [5]. Use case diagrams are used to model the functional requirements only; and these diagrams do not support how to model non functional requirements (NFR) like performance, reliability, maintainability, etc. SysML is a visual modeling language which is used for various process of Requirements Engineering (RE). Among these methods, goal oriented methods have received much attention by RE community because of the following reasons:

1. Goals provide a precise criterion for sufficient completeness of requirements specification

2. Goal models provide an excellent way to communicate requirements to customers etc.

On the basis of our literature review, we identify that goal oriented requirements elicitation process (GOREP) like KAOS, i*, GOIG, and AGORA [5] do not support how to place stakeholders into relevant colloquium in a timely manner using RS. Therefore, the objective of this paper is to propose a Recommender Systems for Software Requirements Negotiation and Prioritization (RSsSRNP) method [18]. In our method, we are integrating RSs so that the stakeholders can easily understood and visualize their requirements in an organized way and can be placed into a relevant colloquium. This paper is organized as follows: In section II, we present an insight into RSs. Section III describes fuzzy set theory. Proposed method is given in Section IV. Case Study is given in section V. Finally, conclusion and future work are given in section VI.

\section{RECOMMENDER SYSTEMS}

Recommender Systems (RSs) can be defined as the system in which "people provide recommendations as inputs, which the system then aggregates and directs to appropriate recipients" [2]. The primary RS came into essence in [2] and since then they are progressing regularly to acquire superior degree of certainty as well as stakeholders comfort. RSs are working successfully in their domain like books, digital products, films, music, movies, TV programs, different news, shopping, and websites based on stakeholders preferences [1]. These systems use analytic technology to compute the probability that a user will purchase one of the products at each place, so that users will receive recommendations for the right products to purchase. A recommender system must be reliable to provide good recommendations and showing information about the recommendations (e.g. explanations, details, etc.). A recommender system can offer a modified information services in different ways; it depends on whether the system has been recording and examining a stakeholder's earlier preferences [1]. Therefore, it motivates us to integrate RSs with requirements elicitation process. In literature [1], we identify different types of RSs like Content Based Filtering (CBF), Collaborative Filtering (CF), and Hybrid System (HS). $\mathrm{CF}$ in further classified into two parts based on users and items i.e. memory based approach and model based approach. In proposed method, we use $\mathrm{CBF}$. 


\section{FUZZY LOGIC}

The concept of fuzzy logic was given by Lotfi A. Zadeh in the year of 1965. In order to calculate vague and imprecise queries fuzzy logic is used. It is a multi-valued logic that uses different values between interval $[0,1]$. According to Zadeh fuzzy set is defined as: "In universe of discourse $U_{x}$, a fuzzy subset $A$ of $U_{x}$ is characterized by a membership function $f$ ${ }_{A}(x)$ where $f(A): U_{x}[0,1]$ ". Fuzzy membership function associates with each member of $X$ of $U_{x}$ of a number of $f(x)$ in the interval $[0,1]$, represents degree of membership function of $\mathrm{X}$ in $\mathrm{A}$. Linguistic variables are words whose values are imprecise e.g., very low, low, average, high, very high etc. To represent linguistic variables we use fuzzy numbers. They give graphical representation of vague queries (imprecise queries). There are several types of fuzzy numbers e.g., trapezoidal fuzzy number, bell shaped fuzzy number, Gaussian fuzzy number, triangular fuzzy number [7, 8].

\section{PROPOSED METHOD}

In this section, we present the proposed method, which are based on Recommender Systems for Software Requirements Negotiation and Prioritization. Proposed method includes the following (see Fig. 1):

1. Identify stakeholder.

2. List of functional requirements (FR) and non functional requirements (NFR).

3. Elicitation of DMs weight using the $L^{-1}-R^{-1}$ inverse function arithmetic principle and graded mean integration representation.

\section{Step 1: Identify stakeholders}

Stakeholder identification is a most important activity of a requirements elicitation process. Therefore, the first step of our method is to identify the primary and secondary stakeholders $[8,10]$. Primary stakeholders include those who are central to any project initiative, i.e., beneficiaries, financial, politicians, sponsors, and decision maker. Secondary stakeholders include developers, experts, operators etc [9].

\section{Step 2: List of functional requirements (FRs) and non functional requirements (NFRs)}

The meaning of FRs and NFRs is given below:

(i) $\mathrm{fr}_{1}$ : printout of bank receipt of students fee; (a) Student details: student name, course, fathers name, faculty/department, (b) Fee slips details: bank scroll number, pay-in-slip, slip date, slip printed by, name of the bank, account id, (c)Fee details: Examination fee, admission fee, library/lab fee, games fee, curricular activities, last date of submission, total amount, and run date.

(ii) $\mathrm{fr}_{2}$ : entry of internal and external marks;

(iii) $\mathrm{fr}_{3}$ : view semester result;

(iv) $\mathrm{fr}_{4}$ : generate examination sitting arrangement;

(v) $\mathrm{fr}_{5}$ : online conduct of examination;

(vi) $\mathrm{fr}_{6}$ : fill examination form; and after successful submission of the form system will generate the following information: (a) roll number, (b) name of the students, (c) examination name, (d) subject code, (e) subject name(s), (f) number of backlogs, if any $(\mathrm{g})$ examination fee(s);

(vii) $\mathrm{fr}_{7}$ : upload any exam related activities;

(viii) $\mathrm{fr}_{8}$ : generate examination hall ticket;

(ix) $\mathrm{fr}_{9}$ : approve examination form;

(x) $\mathrm{fr}_{10}$ : on line payment of examination fee.

Student module $\left(\mathrm{FR}_{1}\right)$ is decomposed into three sub requirements, i.e., $\mathrm{fr}_{1}, \mathrm{fr}_{6}$, and $\mathrm{fr}_{10}$; and there is an AND decomposition among these requirements. Administrative module $\left(\mathrm{FR}_{2}\right)$ is decomposed into three sub-requirements, i.e., $\mathrm{fr}_{7}, \mathrm{fr}_{8}, \mathrm{fr}_{9}$; and there is also an AND decomposition among these requirements. $\mathrm{FR}_{3}$ is decomposed into four subrequirements, i.e., $\mathrm{fr}_{2}, \quad \mathrm{fr}_{3}, \mathrm{fr}_{4}, \quad$ and $\mathrm{fr}_{5}$. Similarly, Trustworthiness (NFR) is further decomposed into three subrequirements, i.e., $\mathrm{nfr}_{1}$ : Security; $\mathrm{nfr}_{2}$ : Reliability; and $\mathrm{nfr}_{3}$ : Performance. There is also an AND decomposition among these requirements. Reliability, i.e., $\mathrm{nfr}_{2}$ is further decomposed into three sub- requirements, i.e., $\mathrm{nfr}_{2-1}$ : recoverability; $\mathrm{nfr}_{2-2}$ : Adaptability; and $\mathrm{nfr}_{2-3}$ : maturity. There is an OR decomposition among these requirements. OR decomposition means that the selection of any requirements leads to the achievement of the parent requirements.

\section{Step 3: Assigning Scores to FRs and NFRs according to DM's}

Apply $\mathrm{L}^{-1}, \mathrm{R}^{-1}$ inverse function arithmetic principle and graded mean integration for the elicitation decision maker's weight [11].

In this paper we apply $L^{-1}, R^{-1}$ function arithmetic principal and graded mean method for the elicitation of decision maker's weight. A brief introduction is given below:

Let $A_{1}=\left(a_{1}, b_{1}, c_{1}\right)$ and $A_{2}=\left(a_{2}, b_{2}, c_{2}\right)$ be two trapezoidal fuzzy numbers as Fig. 1. The addition of $A_{1}$ and $A_{2}$ at h-level is:

$A_{1(h)} \oplus A_{2(h)}=\left(L_{A 1(h)}^{-1}+L_{A 2(h)}^{-1}, L_{A 1(h)}^{-1}+R_{A 2(h)}^{-1}, R_{A 1(h)}^{-1}+\right.$
$L_{A 2(h)}^{-1}, R_{A 1(h)}^{-1}+$
$\left.R_{A 2(h)}^{-1}\right)$




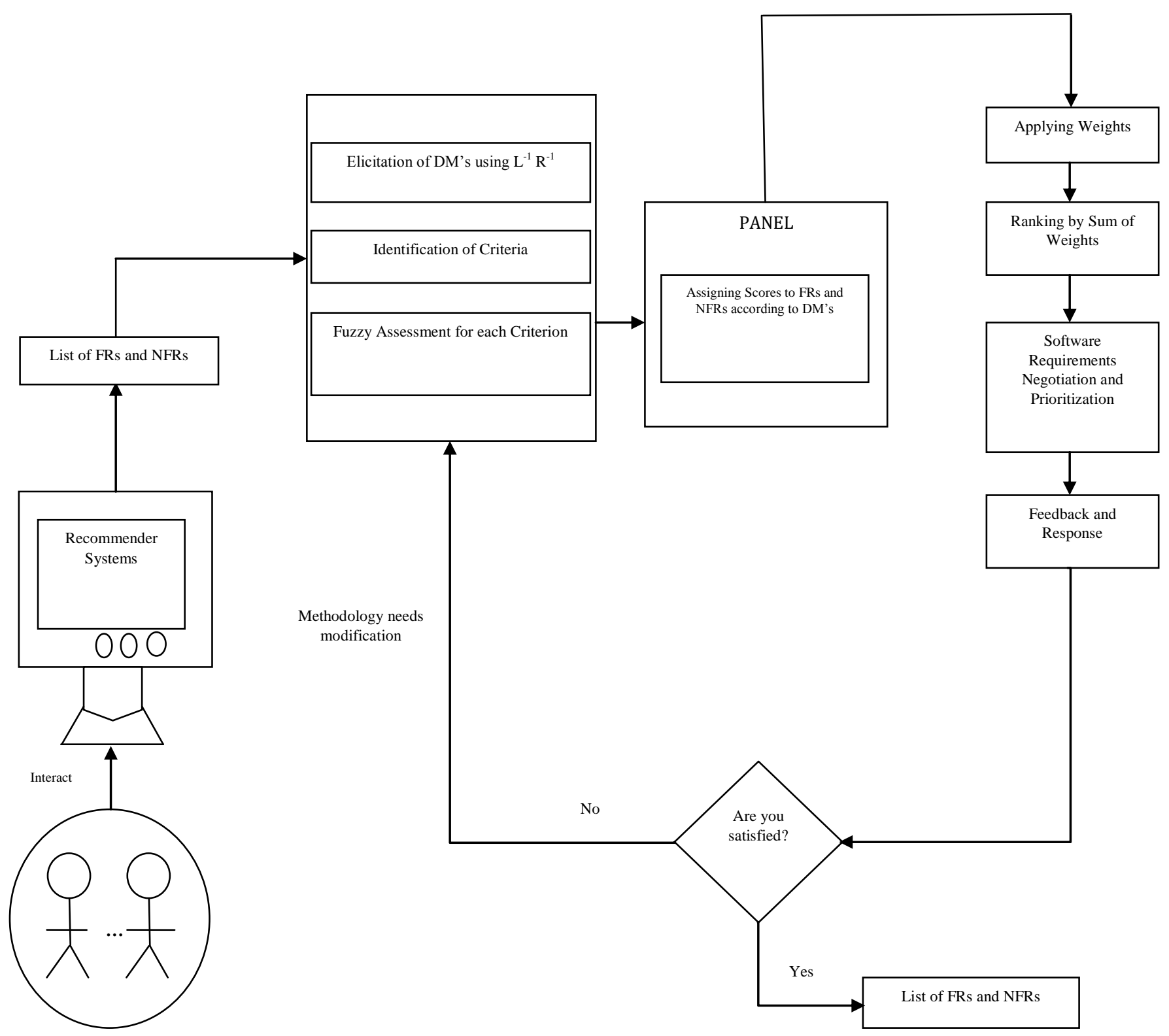

Stakeholders

Fig. 1 Proposed Method 
$L_{A 1}$ and $R_{A 1}$ are the functions $\mathrm{L}$ and $\mathrm{R}$ of fuzzy number $\mathrm{A}_{1}$, respectively. $L_{A 1(h)}^{-1}$ and $R_{A 1(h)}^{-1}$ are the inverse functions of functions $L_{A 1}$ and $R_{A 1}$ at h-level, respectively. $L_{A 2}$ and $R_{A 2}$ are the functions $\mathrm{L}$ and $\mathrm{R}$ of fuzzy number $\mathrm{A}_{2}$, respectively. $L_{A 2(h)}^{-1}$ and $R_{A 2(h)}^{-1}$ are the inverse functions of functions $L_{A 2}$ and $R_{A 2}$ at h-level, respectively.

Suppose the membership functions of $A_{1}=\left(a_{1}, b_{1}, c_{1}\right)$ is

$$
\begin{aligned}
& f_{A 1}(x)= \\
& \left\{\begin{array}{l}
\frac{\left(x-a_{1}\right)}{\left(b_{1}-a_{1}\right)}, a_{1} \leq x \leq b_{1}, \\
\frac{\left(x-c_{1}\right)}{\left(b_{1}-c_{1}\right)}, b_{1} \leq x \leq c_{1}, \\
0, \quad \text { otherwise. }
\end{array}\right\}
\end{aligned}
$$

\section{Since}

$L_{A 1}(x)=\frac{\left(x-a_{1}\right)}{\left(b_{1}-a_{1}\right)}, a_{1} \leq x \leq$

$b_{1}$,

$R_{A 1}(x)=\frac{\left(x-c_{1}\right)}{\left(b_{1}-c_{1}\right)}, b_{1} \leq x \leq$

$c_{1}$,

and

$L_{A 1(h)}^{-1}=b_{1}+\left(b_{1}-a_{1}\right) h, \quad 0 \leq h \leq 1$,

$R_{A 1(h)}^{-1}=c_{1}+\left(b_{1}-c_{1}\right) h, \quad 0 \leq h \leq 1$,

Similarly, suppose the membership function of $A_{2}=\left(a_{2}\right.$, $\left.\mathrm{b}_{2}, \mathrm{c}_{2}\right)$ is

$$
\begin{aligned}
& f_{A 2}(x)= \\
& \left\{\begin{array}{cc}
\frac{\left(x-a_{2}\right)}{\left(b_{2}-a_{2}\right)}, & a_{2} \leq x \leq b_{2}, \\
\frac{\left(x-c_{2}\right)}{\left(b_{2}-c_{2}\right)}, & b_{2} \leq x \leq c_{2}, \\
0, & \text { otherwise. }
\end{array}\right\}
\end{aligned}
$$

Since

$$
\begin{array}{lr}
L_{A 2}(x)=\frac{\left(x-a_{2}\right)}{\left(b_{2}-a_{2}\right)}, & a_{2} \leq x \leq \\
b_{2}, & (6)
\end{array}
$$

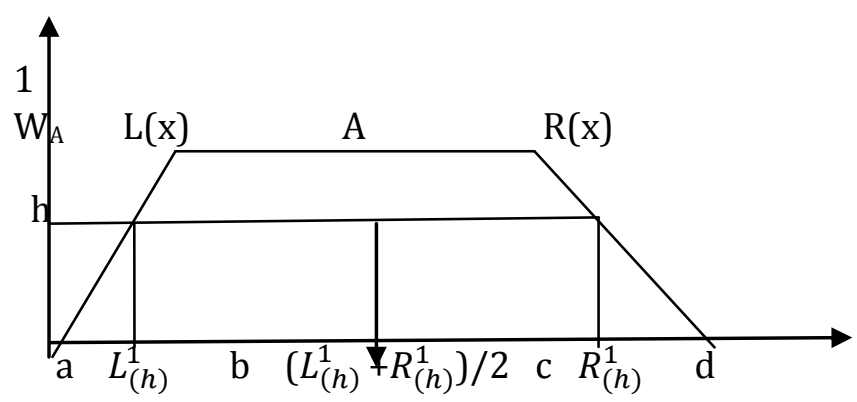

Fig. 2.The graded mean $h$-level of fuzzy number $A=(a, b$, $\left.c, d ; W_{A}\right)_{L R}$

$$
\begin{aligned}
& R_{A 2}(x)=\frac{\left(x-c_{2}\right)}{\left(b_{2}-c_{2}\right)}, \quad b_{2} \leq x \leq \\
& c_{2},
\end{aligned}
$$

and

$$
\begin{array}{ll}
L_{A 2(h)}^{-1}=a_{2}+\left(b_{2}-a_{2}\right) h, & 0 \leq h \leq 1, \\
R_{A 2(h)}^{-1}=c_{2}+\left(b_{2}-c_{2}\right) h, & 0 \leq h \leq 1,
\end{array}
$$

According to Equation 1, we have that

$$
\begin{gathered}
A_{1(h)} \oplus A_{2(h)}=\left(\begin{array}{c}
L_{A 1(h)}^{-1}+L_{A 2(h)}^{-1}, L_{A 1(h)}^{-1}+R_{A 2(h)}^{-1}, R_{A 1(h)}^{-1} \\
\left.+L_{A 2(h)}^{-1}, R_{A 1(h)}^{-1}+R_{A 2(h)}^{-1}\right)
\end{array}\right. \\
=\left[\left(a_{1}+\left(b_{1}-a_{1}\right) h\right)+\right. \\
a 2+b 2-a 2 h, a 1+b 1-a 1 h+c 2+b 2-c 2 h \\
c 1+b 1-c 1 h+a 2+b 2-a 2 h, c 1+b 1-c 1 h+c 2+b 2-c 2 h .
\end{gathered}
$$

Second, we introduce briefly the graded integration representation method. Chen and Hsieh proposed the graded integration representation method of fuzzy numbers $[10,11$, 12] based on the integral value of graded mean h-level of generalized fuzzy number. Here, we describe the meaning as follows.

In general, a generalized fuzzy number A is described as any fuzzy subset of the real line $\mathrm{R}$, whose membership function $\mathrm{u}_{\mathrm{A}}$ satisfies the following conditions.

(1). $u_{A}(x)=0,-\infty<x \leq c$;

(2). $u_{A}(x)$ is strictly increasing on [c, a];

(3). $u_{A}(x)=w, a \leq x \leq b$, where $0<w \leq 1$;

(4). $u_{A}(x)$ is strictly increasing on $[\mathrm{b}, \mathrm{d}]$;

(5). $u_{A}(x)=0, d \leq x \leq \infty$

(6). $u_{A}$ is a continuous mapping from $\mathrm{R}$ to the closed interval $[0,1]$;

Here $\mathrm{a}, \mathrm{b}, \mathrm{c}$, and $\mathrm{d}$ are real numbers. We denote generalized fuzzy number A in Fig .1 as $\left(\mathrm{a}, \mathrm{b}, \mathrm{c}, \mathrm{d} ; W_{A}\right)$ LR. When $W_{A}=1$. We simplify notation as $\mathrm{A}=(\mathrm{a}, \mathrm{b}, \mathrm{c}, \mathrm{d})$ LR (see Fig.

Let $L^{1}$ and $R^{1}$ be the inverse function of the functions $\mathrm{L}$ and $\mathrm{R}$, respectively ; then the graded mean h-level value of generalized number A is $\mathrm{h}\left(L_{(h)}^{1}+R_{(h)}^{1}\right) / 2$ as shown in figure. Then the graded mean integration representation of $A$ is

$$
\begin{gathered}
P(A)=\frac{\int_{0}^{w A}(h(a+(b-a) h+d+(c-d) h) / 2) d h}{\int_{0}^{w A} h d h} \\
=\frac{1}{6}(a+2 b+2 c+d)
\end{gathered}
$$

Here, $\mathrm{a}, \mathrm{b}, \mathrm{c}$ and $\mathrm{d}$ are numbers. We denote generalized fuzzy number $A$ in Fig. 2 as $A=(c, a, b, d)_{L R}$. When $w_{A}=1$, we simplify the notation as $A=(a, b, c, d)_{L R}$. 
Generalized triangular fuzzy number $\mathrm{K}=(\mathrm{a}, \mathrm{b}, \mathrm{c}, \mathrm{d})$ is $\mathrm{a}$ special case of generalized trapezoidal fuzzy number. The graded mean integration representation of the triangular fuzzy number $\mathrm{Y}$ becomes

$\operatorname{TFN}(K)=\frac{1}{6}(a+2 b+2 c+d)$

\section{CASE STUdY}

In this section, we applied the proposed method with help of five decision makers (DMs) opinion on NFR degree assessment of criteria. In this case study, we use five ranking parameters i.e.

Very Low (VL), Low (L), Middle (M), High (H), and Very High (VH) DMs fuzzy assessment parameter is shown in Table 1.

$\operatorname{TFN}(w)=\frac{1}{6}(a+4 b+c)$

(9)

Where, TFN (W) is weights of linguistic variables using TFN and a, b, c are column wise average. Tables 2 assign fuzzy assessment of decision makers for NFRs, and table 4 assign fuzzy assessment of decision makers for FRs.

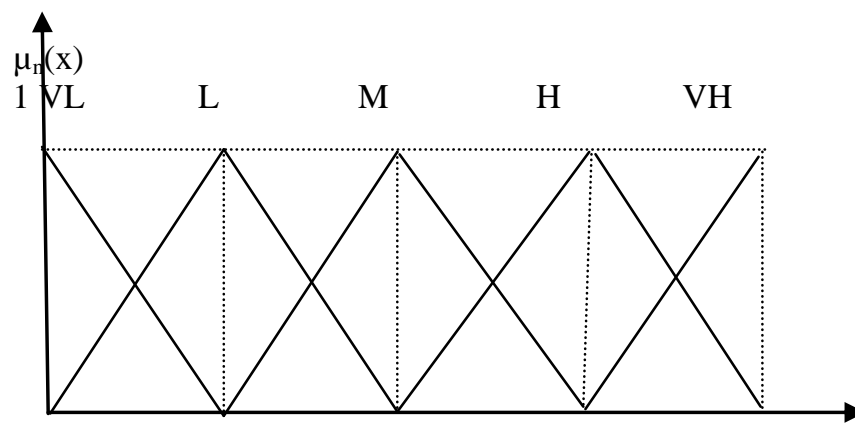

0

0.25

0.50

0.75

1

Fig. 3: Membership function for linguistic variables

(VL, L, M, H, VH) for each FRs and NFRs

Table 1: Linguistic variable set and their TFN (see Fig 1)

\begin{tabular}{llll}
\hline $\begin{array}{l}\text { LINGUISTIC VARIABLE } \\
\text { SET }\end{array}$ & ABBREVIATION & TFN \\
\hline & VL & VERY LOW & $(0,0,0.25)$ \\
L & LOW & $(0,0.25,0.5)$ \\
M & MIDDLE & $(0.25,0.5,0.75)$ \\
H & HIGH & $(0.5,0.75,1)$ \\
VH & VERY HIGH & $(0.75,1,1)$ \\
& & \\
\hline
\end{tabular}

Table 2: Fuzzy assessment of decision makers for NFRs

\begin{tabular}{cccccc}
\hline NFRs & DM $_{1}$ & DM $_{2}$ & DM $_{3}$ & DM $_{\mathbf{4}}$ & DM $_{5}$ \\
\hline Transparency & VH & H & H & M & H \\
Scrutability & H & M & M & L & M \\
Trust & VH & H & VH & VH & H \\
Effectiveness & M & M & L & H & VH \\
Persuasiveness & H & L & M & L & M \\
Efficiency & M & H & VH & H & H \\
Satisfaction & VH & H & VH & VH & M \\
\hline
\end{tabular}

In our proposed work, stakeholders that participate in decision making are identified and we call them $\mathrm{DM}_{1}, \mathrm{DM}_{2}, \mathrm{DM}_{3}$, $\mathrm{DM}_{4}$, and $\mathrm{DM}_{5}$. These decision makers assign vague value to the measuring parameters according to the understanding. Weights for each measuring parameter is calculated as listed in table 3 and table 5.

Table 3: Evaluation of weights for NFRs using Equation (9)

\begin{tabular}{ccccccc}
\hline NFRs & DM $_{1}$ & DM $_{2}$ & DM $_{3}$ & DM $_{4}$ & DM $_{5}$ & WEIGHTS \\
\hline Transparency & VH & H & H & M & H & 0.741 \\
Scrutability & $\mathrm{H}$ & $\mathrm{M}$ & $\mathrm{M}$ & $\mathrm{L}$ & $\mathrm{M}$ & 0.500 \\
Trust & $\mathrm{VH}$ & $\mathrm{H}$ & $\mathrm{VH}$ & $\mathrm{VH}$ & $\mathrm{H}$ & 0.741 \\
Effectiveness & $\mathrm{M}$ & $\mathrm{M}$ & $\mathrm{L}$ & $\mathrm{H}$ & $\mathrm{VH}$ & 0.416 \\
Persuasiveness & $\mathrm{H}$ & $\mathrm{L}$ & $\mathrm{M}$ & $\mathrm{L}$ & $\mathrm{M}$ & 0.450 \\
Efficiency & $\mathrm{M}$ & $\mathrm{H}$ & $\mathrm{VH}$ & $\mathrm{H}$ & $\mathrm{H}$ & 0.733 \\
Satisfaction & $\mathrm{VH}$ & $\mathrm{H}$ & $\mathrm{VH}$ & $\mathrm{VH}$ & $\mathrm{M}$ & 0.825
\end{tabular}

From table 3, we identify, after evaluating of weights for NFRs using equation 9 that satisfaction has the highest priority and effectiveness has the lowest priority. 
Table 4: Fuzzy assessment of decision makers for FRs

\begin{tabular}{cccccc}
\hline FRs & $\mathbf{D M}_{\mathbf{1}}$ & $\mathbf{D M}_{\mathbf{2}}$ & $\mathbf{D M}_{\mathbf{3}}$ & $\mathbf{D M}_{\mathbf{4}}$ & $\mathbf{D M}_{\mathbf{5}}$ \\
\hline $\mathrm{fr}_{1}$ & $\mathrm{VH}$ & $\mathrm{H}$ & $\mathrm{H}$ & $\mathrm{VH}$ & $\mathrm{H}$ \\
$\mathrm{Fr}_{2}$ & $\mathrm{M}$ & $\mathrm{H}$ & $\mathrm{M}$ & $\mathrm{L}$ & $\mathrm{M}$ \\
$\mathrm{Fr}_{3}$ & $\mathrm{H}$ & $\mathrm{H}$ & $\mathrm{VH}$ & $\mathrm{H}$ & $\mathrm{VH}$ \\
$\mathrm{Fr}_{4}$ & $\mathrm{M}$ & $\mathrm{H}$ & $\mathrm{H}$ & $\mathrm{M}$ & $\mathrm{M}$ \\
$\mathrm{Fr}_{5}$ & $\mathrm{H}$ & $\mathrm{M}$ & $\mathrm{L}$ & $\mathrm{M}$ & $\mathrm{H}$ \\
$\mathrm{Fr}_{6}$ & $\mathrm{H}$ & $\mathrm{M}$ & $\mathrm{H}$ & $\mathrm{H}$ & $\mathrm{VH}$ \\
$\mathrm{Fr}_{7}$ & $\mathrm{H}$ & $\mathrm{H}$ & $\mathrm{VH}$ & $\mathrm{H}$ & $\mathrm{M}$ \\
$\mathrm{Fr}_{8}$ & $\mathrm{VH}$ & $\mathrm{VH}$ & $\mathrm{M}$ & $\mathrm{H}$ & $\mathrm{VH}$ \\
$\mathrm{Fr}_{9}$ & $\mathrm{H}$ & $\mathrm{M}$ & $\mathrm{L}$ & $\mathrm{VH}$ & $\mathrm{H}$ \\
$\mathrm{Fr}_{10}$ & $\mathrm{H}$ & $\mathrm{VH}$ & $\mathrm{VL}$ & $\mathrm{H}$ & $\mathrm{L}$ \\
\hline
\end{tabular}

Table 5: Evaluation of weights for FRs using Equation (9)

\begin{tabular}{ccccccc}
\hline FRs & DM $_{\mathbf{1}}$ & DM $_{\mathbf{2}}$ & DM $_{\mathbf{3}}$ & DM $_{\mathbf{4}}$ & DM $_{\mathbf{5}}$ & WEIGHTS \\
\hline $\mathrm{fr}_{1}$ & $\mathrm{VH}$ & $\mathrm{H}$ & $\mathrm{H}$ & $\mathrm{VH}$ & $\mathrm{H}$ & 0.833 \\
$\mathrm{Fr}_{2}$ & $\mathrm{M}$ & $\mathrm{H}$ & $\mathrm{M}$ & $\mathrm{L}$ & $\mathrm{M}$ & 0.550 \\
$\mathrm{Fr}_{3}$ & $\mathrm{H}$ & $\mathrm{H}$ & $\mathrm{VH}$ & $\mathrm{H}$ & $\mathrm{VH}$ & 0.833 \\
$\mathrm{Fr}_{4}$ & $\mathrm{M}$ & $\mathrm{H}$ & $\mathrm{H}$ & $\mathrm{M}$ & $\mathrm{M}$ & 0.600 \\
$\mathrm{Fr}_{5}$ & $\mathrm{H}$ & $\mathrm{M}$ & $\mathrm{L}$ & $\mathrm{M}$ & $\mathrm{H}$ & 0.550 \\
$\mathrm{Fr}_{6}$ & $\mathrm{H}$ & $\mathrm{M}$ & $\mathrm{H}$ & $\mathrm{H}$ & $\mathrm{VH}$ & 0.741 \\
$\mathrm{Fr}_{7}$ & $\mathrm{H}$ & $\mathrm{H}$ & $\mathrm{VH}$ & $\mathrm{H}$ & $\mathrm{M}$ & 0.741 \\
$\mathrm{Fr}_{8}$ & $\mathrm{VH}$ & $\mathrm{VH}$ & $\mathrm{M}$ & $\mathrm{H}$ & $\mathrm{VH}$ & 0.825 \\
$\mathrm{Fr}_{9}$ & $\mathrm{H}$ & $\mathrm{M}$ & $\mathrm{L}$ & $\mathrm{VH}$ & $\mathrm{H}$ & 0.641 \\
$\mathrm{Fr}_{10}$ & $\mathrm{H}$ & $\mathrm{VH}$ & $\mathrm{VL}$ & $\mathrm{H}$ & $\mathrm{L}$ & 0.558 \\
\hline
\end{tabular}

From table 5, we identify, after evaluating of weights for FRs using equation 9 that fr 1 and fr 3 has the highest priority and fr2 and fr5 has the lowest priority.

\section{CONCLUSION AND FUTURE WORK}

In this paper, we have proposed a method based on Recommender Systems for Software Requirements Negotiation and Prioritization. The proposed method includes the following steps: identify stakeholders, list of FRs and NFRs, eliciting of DM's using $\mathrm{L}^{-1} \mathrm{R}^{-1}$ inverse function arithmetic principle and graded mean integration representation for finding the Institute Examination System's requirements and prioritize these requirements according to the stakeholders. In our case study, we identify that $\mathrm{fr}_{1}$ and $\mathrm{fr}_{3}$ has the highest priority and $\mathrm{fr}_{2}$ and $\mathrm{fr}_{5}$ has the lowest priority and satisfaction has the highest priority and effectiveness has the lowest priority. Future work includes the following:

1. To apply proposed method in different modules of IES.

2. To present the comparative study between various goals oriented requirements elicitation process.

3. To extend the proposed method by using MultiCriteria Decision Making methods [17] like TOPSIS, AHP etc; and to design a hybrid RSs [1] by using an efficient method for mining frequency item sets [16].

\section{REFERENCES}

[1] Rana C and Jain S.K, "A Study of Dynamic Features of Recommender Systems," Artificial Intelligent Rev, pp. 141-153, Springer, November 2012.

[2] Resnick P and Varian HR, "Recommender Systems," Communication ACM, pp. 56-58, 1997.

[3] Sadiq $M$ and Jain S.K., "Stakeholders Identification Methods in Goal Oriented Requirements Elicitation Process", Fifth IEEE International Workshop on Requirements Prioritization and Communication at IEEE International Requirements Engineering Conference (RE), pp. 25-33, 2014 Karlskrona, Sweden.

[4] Kotonya, G. and Sommerville, I., "Requirements Engineering, Process and Techniques", Willy New York 1998.

[5] Sadiq M. and Jain S.K., "A Fuzzy Based Approach for the Selection in Goal Oriented Requirements Elicitation Process", International Journal of System Assurance Engineering and Management, Springer, 2014.

[6] Sadiq Mohd, Jain S.K, "Applying Fuzzy Preference Relation for Requirements Prioritization in Goal Oriented Requirement".

[7] Sadiq Mohd, "Prediction of Software Project Effort Using Fuzzy Logic", IEEE $3^{\text {rd }}$ International Conference on Electronics, Computer Technology, pp. 353-358, 2014.

[8] Sadiq M and Jain S.K., "A Fuzzy Based Approach for Requirements Prioritization in Goal Oriented Requirements Elicitation Process", International Conference of Software Engineering and Knowledge Engineering (SEKE), pp. 54-58, 2013 USA.

[9] Sadiq M and Jain S.K., "Stakeholders Identification Methods in Goal Oriented Requirements Elicitation Process", Fifth IEEE International Workshop on Requirements Prioritization and Communication at IEEE International Requirements Engineering Conference (RE), pp. 25-33, 2014 Karlskrona, Sweden.

[10] Sadiq M. and Jain S.K., "A Fuzzy Based Approach for the Selection in Goal Oriented Requirements Elicitation Process", International Journal of System Assurance Engineering and Management, Springer, 2014.

[11] Z-p. Fan, Y. Liu, “A Method for Group Decision-Making Based on Multi-Granularity Uncertain Linguistic Information", Expert Systems with Applications, pp. 4000-4008, 2010.

[12] Choi K, Yoo D, Kim G, and Suh Y, "A Hybrid Online Product Recommendation System: Combining Implicit Rating Based Collaborative Filtering and Sequential Pattern Analysis", Electronic Commerce Research and Applications, 2012.

[13] Lee S.K, Cho Y.H, and Kim S.H, "Collaborative Filtering with Ordinal Scale-Based Implicit-Ratings for Mobile Music Recommendations", Information Sciences, pp. 2142-2155, 2010.

[14] Nunez-Valdez E.R, Cueva-Lovelle J.M, SanjuanMartinez O, Garcia-Diaz V, Ordonez P, and Montenegro-Marin C.E., "Implicit Feedback TYechniques on Recoomender Systems Apllied to 
Electronic Books", Computers in Human Behavior, pp. 1186-1193, 2012.

[15] Bobadilla J, Ortega F, Hernando A, and Gutierrez A, "Recommender Systems Survey", Knowledge Based Systems, University Politecnica de Madrid, Ctra. De Valencia, Madrid, Spain, pp. 109-132, 2013.

[16] Supatra S. and Boonjing V, "IIS Mine: A New Efficient Method for Mining Frequency Item Sets", "Maejo International Journal of Science and Technology", pp. 130-151, 23 April 2012.
[17] Tilahun S.L and Choon Ong H, "Fuzzy Preference of Multi Decision-Makers in Solving Multi Objective Optimization Problems using Generic Algorithm", "Maejo International Journal of Science and Technology”, pp. 224-237, 23 June 2012.

[18] Castro-Herrera C, Duan C, Cleland-Huang J, and Mobasher B, "Using Data Mining and Recommender Systems to Facilitate Large-Scale, Open, and Inclusive Requirements Elicitation Process", $16^{\text {th }}$ IEEE International Requirements Engineering Conference, pp. 165-168, 8-12 September 2008, Catalunya. 